\title{
The Local Provision of Restorative Justice in Scotland: an Exploratory Empirical Study
}

\author{
Giuseppe Maglione $^{1}$ (D) Jamie Buchan ${ }^{1} \cdot$ Laura Robertson $^{1}$ \\ Accepted: 4 November 2020 / Published online: 27 November 2020 \\ (C) The Author(s) 2020
}

\begin{abstract}
This article presents the results of the first empirical qualitative research on the provision of restorative justice (RJ) in Scotland, based on interviews with 14 practitioners. In Scotland, RJ has attracted the attention of penal reformers and practitioners since the late 1980s, offering an alternative to criminal justice practices based on retribution and/or rehabilitation whilst promising to reduce reoffending and heal people harmed by crime. In 2017, the Scottish Government has fully recognized the existence of RJ by issuing the first national 'Guidance' for the delivery of this process, followed by an ambitious 'Action Plan'. In spite of such a long-lasting interest and recent policy recognition, there is a lack of knowledge regarding the organization and actual delivery of RJ in Scotland. In fact, research on this subject is scant, anecdotal and dated. This article addresses this knowledge gap by presenting original data on the provision of RJ within Scottish local authorities. The findings show similar understandings of RJ, context-specific organizational models and common systemic challenges characterizing RJ providers, generating evidence to critically assess recent Scottish policy on RJ, whilst drawing implications with relevance for the development of RJ across Europe.
\end{abstract}

Keywords Restorative justice $\cdot$ Community justice $\cdot$ Qualitative interviews $\cdot$ System-level challenges $\cdot$ Scotland

\section{Introduction and Objectives}

Criminal justice scholars have hailed restorative justice (RJ) as one of 'the most significant developments in criminal justice and criminological practice and thinking' (Crawford and Newburn 2003: 19) over the last 30 years, globally. The diffusion of practices inscribed under the label of 'RJ' has been slow but relentless, as evidenced by the development of ad hoc

Giuseppe Maglione

G.Maglione@napier.ac.uk

1 School of Applied Sciences, Edinburgh Napier University, Sighthill Campus, Edinburgh EH11 4BN, UK 
policy, growth in public awareness and proliferation of academic research on this subject (Wood and Suzuki 2016).

In Scotland, processes involving a facilitated dialogue between victims and offenders, aiming to repair the harm caused by crime, have attracted the attention of penal reformers and practitioners since the late 1980s (Warner 1992). Such processes, originally defined as 'mediation and reparation' programs and then rebranded as 'RJ' during the 1990s (Miers 2004), have offered an alternative to criminal justice practices based on retribution and/or rehabilitation whilst promising to reduce reoffending and heal people harmed by crime. Recently, the Scottish Government has fully recognized the existence of RJ by issuing the first national 'Guidance for the Delivery of Restorative Justice' in a bid to advance the development of RJ services in a 'coherent, consistent, victim-focused manner' (Scottish Government 2017: 2). The Guidance has then been followed up by the first 'Restorative justice: Action Plan' which aims to guide the nationwide expansion of RJ (Scottish Government 2019: 3).

In spite of such a long-lasting interest and recent thrust of policy recognition, which is coherent with recent European efforts to regulate $\mathrm{RJ},{ }^{1}$ there is a lack of updated and in-depth knowledge regarding the organization and delivery of RJ in Scotland. In fact, research on this subject is rather scant, anecdotal and dated (Kearney et al. 2006; Kirkwood 2009). This is an obstacle for the evidenceinformed development of RJ as well as for sharing best practices and tackling collectively the challenges that RJ providers may face.

This study addresses this knowledge gap through an empirical qualitative research on the provision of RJ in Scotland within local authorities, ${ }^{2}$ focussing on possible common patterns, gaps and best practices. Our aim is to generate evidence useful to address critically the implementation of the recent policy on RJ whilst enabling comparisons between Scotland and other countries with more established RJ practice and policy in place (e.g. Norway and Belgium). Additionally, we seek to provide RJ practitioners with material which could be used to reflect on their work, on the challenges they face and on the possible ways to tackle them.

After an overview of the historical background, recent policy developments and existing research on Scottish RJ, the article outlines our methodology. It then presents the key results under four headings - practitioners' understandings of RJ, organizational models, system-level challenges and opportunities/recommendations. The empirical results are then discussed in light of the criminological literature, focussing on the relationships between RJ and criminal justice as well as on the impact of specific organizational and political dynamics on shaping RJ in Scotland. Finally the article considers the implications for practice, policy and research, at national and European level.

\footnotetext{
${ }^{1}$ Namely the Directive 2012/29/EU of the European Parliament and the Council of 25 October 2012 establishing minimum standards on the rights, support and protection of victims of crime and the Council of Europe Recommendation $\mathrm{CM} / \operatorname{Rec}(2018) 8$ of the Committee of Ministers to member States concerning restorative justice in criminal matters

${ }^{2}$ Local government in Scotland is organized through 32 unitary local authorities which provide public services (e.g. education, social care, waste management, etc.). Local authorities operate largely independently of Scotland's central government and are accountable to their electorates for the services they provide. They are not local judicial authorities, but do provide much of the organizational infrastructure for the local provision of justice (see also footnotes 8 and 9)
} 


\section{Background}

\section{History}

Similarly to the rest of the UK (and Europe), in Scotland, the development of RJ was trailblazed by sparse mediation and reparation projects run by third sector organizations (e.g. Sacro ${ }^{3}$ ), in the late 1980s and throughout the 1990s (Marshall 1999: 16; Miers 2004: 27). However, whilst, elsewhere in the UK, similar projects turned into established services backed up by ad hoc policy (i.e. Justice (Northern Ireland) Act 2002: §35A; Crime and Courts Act (England \& Wales) 2013: Sch. 16.2.5), in Scotland the expansion of such services has been much slower and has had very limited impact on the local criminal justice system (Miers 2004: 28).

Early Scottish mediation and reparation projects were diversionary schemes to which the prosecutors could refer less serious offences, often considering the victim as an optional participant (SCCJR \& Viewpoint 2009). This approach continued through the early 2000s, amid rising concern over youth crime and antisocial behaviour (McAra 2005; Croall 2006). In this period, the expression 'restorative justice' came to replace 'mediation and reparation' within policy, with the Scottish Government enacting some declarations of principles on the use of RJ, mainly within the youth justice area (Scottish Government 2002a, 2002b, 2005, 2008). At the same time and still within the realm of youth RJ, Scottish police introduced 'restorative warnings' (Scottish Government, Children's Reporter and Association of Chief Police Officers in Scotland 2004) primarily focussed on making young offenders aware of the impact of their (petty) offences, but lacking the direct involvement of the victim.

More recently, a crucial anchorage for youth RJ has been provided by the development of the 'Whole System Approach' (WSA), a Scottish binding policy framework for youth justice (Scottish Government 2015). The WSA (rolled out nationally in 2011) was designed to divert young people who offend from statutory measures, prosecution and custody, through the use of early and effective intervention, diversionary measures and community alternatives (Robertson 2017; Gillon 2018; Benbow 2019). As a multi-agency approach implemented at a local level, it involves a range of partner agencies (e.g. police, prosecutors, social work education and third sector organizations) and is premised upon addressing children's individual needs ${ }^{4}$ (see Centre for Youth and Criminal Justice (2018)).

In adult criminal justice, the Criminal Justice and Licensing (Scotland) Act (2010) has created a policy basis for RJ in community justice, as a possible post-sentencing instrument. The Act introduced the Community Payback Order, a flexible community penalty within which RJ can be linked to one of the requirements imposed on the offender, e.g. as part of a supervision or programme requirement. Supervising social workers may also refer the sentenced person to RJ informally as part of ordinary supervision. However, this Act does not refer explicitly to RJ or make specific provisions about it.

\footnotetext{
${ }_{3}^{3}$ Sacro (Safeguarding Communities - Reducing Offending, formerly the Scottish Association for the Care and Resettlement of Offenders) is a Scottish charity active in the criminal justice area

${ }^{4}$ Although there are similarities between WSA meetings and Northern Irish youth conferences (they both involve a multi-agency approach to youth crime/antisocial behaviour), these are significantly different instruments. WSA meetings are planning meetings attended only by referrers and providers of services whilst youth conferences involve also the young person and the victim, that is, they provide the (RJ) service.
} 


\section{Recent Policy Developments}

A significant change within this context may be represented by the 'Guidance for the Delivery of Restorative Justice in Scotland' (Scottish Government 2017) ('the Guidance'). This is the first ad hoc statutory policy ${ }^{5}$ on RJ in Scotland, aiming to ensure that, where available, RJ is delivered in a coherent, consistent, victim-focused manner, for both young people and adults, in line with the Directive 2012/29/EU of the European Parliament and the Council establishing minimum standards on the rights, support and protection of victims of crime. ${ }^{6}$ The Guidance is articulated in two parts, the first providing definitions, key principles and 'requirements for service providers and facilitators' and the second on 'conducting a restorative justice process'. In this document, an 'official' definition of RJ is given: 'a process of independent, facilitated contact, which supports constructive dialogue between a victim and a person who has harmed (whether this be an adult, a child, a young person or a representative of a corporate or other body) arising from an offence or alleged offence' (2017: 6).

The Guidance states that RJ's main purpose is to give 'victims a voice within a safe and supportive setting and giving them a sense of closure' whilst providing 'those who have harmed with an opportunity to consider the impact of their crime and take responsibility for it, with the aim of reducing the likelihood of re-offending' (2017: 6). It then asserts well-known requirements for RJ in practice such as voluntary access, confidentiality, appropriate and empowering nature, and not directed at establishing guilt (i.e. RJ can take place only when 'the person who has harmed takes responsibility for the harm caused and its consequences’ (2017: 10)). The language used by the Guidance warrants reflection; it combines criminal justice concepts such as 'offence' and 'victim' (2017: 2) and RJ jargon (e.g. 'the person who has harmed', 'empowerment' and 'closure' (2017: 6-10)), mirroring the language used by the Directive 2012/29/EU.

Overall, the Guidance frames RJ as a victim-sensitive criminal justice mechanism (cf. Daly 2016) which can take different forms based on the specifics of the offence under consideration: direct face-to-face meetings, 'shuttle dialogue', apology letters, etc.

In 2019, the Scottish Government followed up the Guidance with a 'Restorative Justice: Action Plan'. This commits the Scottish Government 'to have [high quality] Restorative Justice services widely available across Scotland by 2023' (2019: 3). The Action Plan encourages a 'partnership approach involving organisations across the Scottish justice sector' which should then lead to developing a 'nationally-available model for RJ' (2019: 9). It also considers some of the challenges which may hinder such an ambitious plan, namely the lack of public awareness, issues with information sharing and lack of resources and of training opportunities (2019: 8). Together, the national Guidance and the Action Plan represent the Scottish Government's most overt and thoroughly worked-out commitment to RJ (including in adult criminal justice) to date.

\section{Extant Research}

Despite the long-lasting interest around RJ and the recent thrust of relevant policy, the empirical research on RJ in Scotland is scant and outdated and consists mainly of smallscale (often internal) evaluative analyses of early RJ services.

\footnotetext{
5 The Guidance's legal status is that of a non-binding policy (there are no sanctions for infringements), intended for RJ practitioners, providers and referrers

${ }^{6}$ Implemented in Scotland through The Victims and Witnesses (Scotland) Act (2014) which at Section 5 explicitly enables Scottish Ministers to issue guidance on RJ
} 
Possibly the earliest research in the field was the 1992 review of Sacro's reparation and mediation pilot projects. Findings suggested that although these projects contemplated the production of benefits to both victims and offenders, two main problems arose, both related to the diversionary role of reparation and mediation: restricted access for victims and the extension of the criminal justice net (Warner 1992: 204). Sacro executed two other internal evaluations on its services mainly focussing on their 'effectiveness'. The first (Nicol et al. 2006) found, inter alia, that the person harmed by the offence participated in a restorative process in $42 \%$ of cases, whilst the second (Kearney, Kirkwood \& MacFarlane 2009) reported that both parties were willing to participate in $35 \%$ of cases; of those, $82 \%$ resulted in mutual agreement on how to deal with the offence. In terms of external evaluations, Dutton and Whyte (2006) researched Glasgow's youth RJ services, finding that, in those cases where the person harmed was contacted, $56 \%$ participated in a restorative process and levels of satisfaction were high.

More recent, and more relevant to our research, is the Restorative Justice/Practice Research Working Group survey on Scottish criminal justice professionals' understanding of RJ (SCCJR \& Viewpoint 2009). The findings showed a differentiation of knowledge and use across respondents making 'difficult for any clear regulatory function or model to apply' (SCCJR \& Viewpoint 2009: 2). In terms of organization of RJ services, it was observed that this was patchy and that referrers were mainly the Children's Reporter, ${ }^{7}$ the police and occasionally social workers. These findings were partly confirmed in 2018 in a survey by the Scottish Government and Community Justice Scotland, on the delivery of RJ (Scottish Government 2018). The survey found that only around half of Scotland's local authorities provided RJ services; where RJ was provided, this was usually by social work, with third sector providers (particularly Sacro) the second most common provider. The survey also identified information sharing, public awareness and lack of training as the key challenges for the future development of Scottish RJ.

The limited amount, mainly evaluative nature and generally survey-based methods of the extant research, does not afford an updated and in-depth picture of what is actually happening in the field, particularly considering recent policy developments. The impact of such policy and more broadly the future of RJ depend on the identification of good practices existing locally and of any gap in the provision of RJ. Our research aims to address this knowledge gap, by generating qualitative insights which may contribute to a critical development of RJ in Scotland whilst presenting implications relevant for the advancement of RJ also in other European countries.

\section{Methodology}

This work is an empirical exploration of how RJ is provided in Scotland, within local authorities, ${ }^{8}$ focussing on how it is understood by those who deliver RJ and on how such understandings are filtered and then operationalized by the fabric of social transactions which practitioners and organizations enact daily (Cotterrell 2007).

\footnotetext{
${ }^{7}$ Scottish child welfare agent and (in some cases) youth public prosecutor, supported by the Scottish Children's Reporter Administration

${ }^{8}$ Local authorities are not the only context within which RJ is provided in Scotland. In fact, there is anecdotal knowledge of RJ being delivered within prisons as well as within schools (Scottish Justice Matters 2017)
} 
This research addresses the following research questions: (1) How do service providers ${ }^{9}$ understand RJ, its values, aims and goals? (2) What are the common patterns (if any) across the provision of RJ (e.g. organization, training, approach, capacity)? (3) What are the common limitations (if any) in the delivery of RJ in Scotland? (4) How do providers interpret and apply the recent Scottish Guidance on RJ? (5) Which factors affect the application of RJ policy in context?

Fieldwork took place between October 2018 and May 2019. The population was sampled purposively in two phases. First, we contacted all (32) Scottish local authorities through their community justice partnership arrangements ${ }^{10}$ in order to scope as many providers as possible; then, we carried out interviews with all RJ providers identified during the initial mapping exercise in order to outline a full picture of the current RJ practice delivery in Scotland. We found out that RJ is available in 12 local authorities through 13 providers (in all cases constituted by professional practitioners, i.e. no volunteer practitioners were identified). This finding differs from that of the Scottish Government survey (2018), in which 16 respondents said RJ was available in their local authority. Possible explanations for this include different patterns of response in the two studies, changes to provision in the short interval between the fieldwork for the two studies and the fact that the government survey approached community justice and youth justice teams separately within each local authority area (possibly counting some providers twice).

Data was generated empirically by in-person semi-structured audio-recorded interviews with providers indicated by the local authority. Individual respondents answered pre-set openended questions. We carried out interviews with 14 practitioners. Interviews were based on an interview guide in order to explore comprehensively respondents' views across different local authorities. This approach also enabled in-depth comparisons useful to identifying best practices and gaps. The items in the guide comprised the core questions (understandings, organization, policy implementation) and associated relevant questions. Ethics approval was secured from the Edinburgh Napier University Research Integrity Committee. Due to the nonsensitive nature of the data gathered (professional views), from an ethical viewpoint the research presented only general issues of confidentiality (achieved through data anonymisation), data storage (password protected storage and GDPR compliant), withdrawal from the project (possible before anonymisation, 1 month after the interview, without giving a reason) and positionality (due to the PI and Co-PI's links with research/advocacy networks in Scotland, the participants' recruitment and interviews were conducted by the research fellow).

The data were analysed using thematic analysis (Braun and Clarke 2006) - a highly adaptable and grounded approach to analysing qualitative data. The analysis was carried out iteratively and concurrently with the fieldwork, using QSR NVivo. Data was marginally cleaned in order to make it as comprehensible and useful as possible, by removing irrelevant repetitions within sentences, adding in square brackets implicit subjects, adding punctuation and correcting typos.

In terms of limitations, apart from the general constraints of qualitative empirical research (O'Reilly and Kiyimba 2015), the possibility of variations in levels of cooperation across

\footnotetext{
${ }^{9}$ We define RJ 'practitioners' those people who deliver RJ 'services'-i.e. facilitation of RJ processes and related work - and 'providers' the dedicated (but not necessarily highly structured) RJ units that they constitute within local authorities. Clearly, in practice these overlap

${ }^{10}$ Scotland is unusual within the UK in that services for and supervision of offenders in the community are provided and coordinated not by a probation service, but by local authority social work departments which work in partnership with third sector organizations or other public bodies.
} 
gatekeepers (i.e. local authorities) should be acknowledged, as a matter of caution; hence, the mapping of RJ providers may not be exhaustive.

\section{Results}

This section gives an overview of the main results of our study with a focus on (1) practitioners' understandings of RJ; (2) organization of the provision; (3) challenges and (4) opportunities and recommendations to improve the delivery of RJ in Scotland.

\section{Understandings of Restorative Justice}

Interviewees stressed that RJ to them is firstly an overarching value-based approach to a wide range of problematic situations (offences, antisocial behaviour, conflicts) which informs their work widely and deeply, and only secondarily a specific set of practices (i.e. victim-offender mediation, conferences, circles, victim awareness, apology letters) which directly embody those values.

"[RJ is a] whole philosophy [which] is kind of used on a daily basis" I. E (in-house, youth RJ)

"But I think because of the way we all think about RJ and the way we work with RJ it just runs through everything that we do. It's not a specific here it is, here's a RJ conference or here's a RJ programme it's like it runs through the thread of everything cause our whole service is built on the building blocks of RJ" I. I (in-house, adult and youth RJ)

Interviewees particularly emphasized the voluntary, needs-based and dialogic nature of RJ:

"Where somebody is referred we'd assess their needs [...] Where there's, within every referral we would consider a restorative approach". I. B (third sector, youth RJ) "with RJ you have to ensure that the person harmed and the person responsible want to come together for positive reasons" I.J1 (third sector, adult RJ)

"Cause it's not about just saying 'oh they just need to meet them and apologise'. It's about $O K$ if that comes out, that's great, as long as there's a constructive dialogue between the people”. I. A (in-house, adult RJ)

This approach, particularly when it involves young people, is driven by a searing critique of the criminal justice system:

"I don't want to see youngsters not given that opportunity or not afforded that opportunity and then pushed through the criminal justice system, which, in my experience, makes a lot of people worse" I. C (third sector, youth RJ)

The issue of non-labelling (or less labelling) language was also recurrently identified by participants as a key aspect of RJ (often explicitly contrasted with criminal justice language), highlighting how clear-cut definitions of people as 'victims' or 'offenders' (even in the context of RJ itself) are problematic:

"We don't really tend to call young people offenders. Really move away from that. We just call them young people really” I. D (third sector, youth RJ) 
"We try to look at the terminology we use [we] talk about the person who has harmed and the person who has been harmed" I. H (in-house, youth RJ)

"it's not always cut and dry that there's one person harmed or one person responsible so it's more [...] getting the two parties together and being able to just sit down and discuss what's been happening” I.J2 (third sector, adult RJ)

In terms of specific RJ practices, interviewees reported familiarity with a wide range of interventions, from face-to-face encounters, to shuttle processes, to apology letters:

"So we try and work with both sides equally. Persons harmed and persons responsible. In separate parallel processes so sort of bringing them together or facilitating indirect communication where it's not appropriate for them to come together" I.K1 (third sector, adult and youth RJ)

"We might be doing an apology letter quite often if we can't have the 'sit down chat'” I. F (in-house, youth RJ)

They also showed acute awareness of the flexibility of RJ as a set of values and the fact that it can be understood differently and used to justify significantly different and even contradictory interventions, particularly on youth crime and antisocial behaviour:

"People band that about 'yeah we do RJ" - but do [be] specific about what RJ it is that you're doing. Is it RJ talk? Is it RJ shuttle mediation? Is it face to face? Or is it just an ethos?" I. I (in-house, adult and youth RJ)

"The police who sit at the table as well, they would say that they do engage in RJ. And I would argue they're not [...] I've spoken to one young person who has been part of that and it's basically a finger wagging exercise where you get told off again about their behaviour" I. G (in-house, youth RJ)

\section{Organization}

RJ provided in Scotland by local authorities, either in-house or commissioned to third sector organizations, is fundamentally youth RJ, with only 2 providers out of 13 offering RJ for both young people and adults (interviewees I. I, I.K1 and I.K2) and 3 (two of which now discontinued) only for adults (interviewees I.J1, I.J2, I.J3 and I.A). By 'youth' and/or 'adult' RJ, we refer to how interviewees defined their work. Youth RJ providers usually deal with people aged 8-17 involved in offending even though, sometimes, they also cater for people aged above 17. In fact, what makes the difference between 'youth' and 'adult' providers is how they source cases (see below) rather than the age groups involved. All youth RJ providers deal with 'minor' offences whilst the adult ones would consider a wider range of cases. The organization of referral routes emerges as a key logistical aspect which impacts significantly on how RJ is practiced.

\section{Referrals: Whole System Approach and Early and Effective Intervention}

One specific aspect of (youth) RJ provision in Scotland is its integration with the WSA. The WSA consists of three strands: 'Early and Effective Intervention' (EEI) designed to reduce unnecessary referrals to the Children's Hearing System ${ }^{11}$ and deal with lower tariff offending

${ }^{11}$ Scotland's care and justice system for children and young people 
which does not require compulsory measures; 'Diversion from Prosecution' (DP), which seeks to redirect children from formal systems such as Procurator Fiscal ${ }^{12}$ and Courts; and 'Reintegration and Transitions', for children who are returning to their communities following a period in secure care or custody (Scottish Government 2016).

A young person can be referred to a RJ intervention via both EEI and DP processes. Referrals to RJ providers can be made by the police, multi-agency meetings/WSA coordinators (EEI) or by a Procurator Fiscal (DP). Referrals to RJ can also be made by social work or the Scottish Children's Reporter Administration. The referrer is usually also responsible for contacting the person harmed to see if they would like to be involved in a RJ process. The RJ provider will then contact the person harmed willing to engage, to furnish them with information on the service.

"So, they [referrers] have the kind of Whole System Approach model. Her main remit is to provide court support and support individuals that are deemed high risk but other parts of her team cover Early and Effective Interventions and are the partners of the Whole System Approach [...]. So the main resource of referrals is there's a referral group led by Police Scotland and social work where the young people [8-17], children as well, young folk, coming through, are known to police, have been involved in an incident or had an offence they would be screened and they would be discussed at a multi-agency group where RJ provider would be represented" I. B (third sector, youth RJ) "[if the young person is willing to accept responsibility] I then ask the referrer to contact the person harmed and ask if it's ok that I write to them. The letter says if you've not contacted us within a week from this letter if you don't want me to contact them" I. F (in-house, youth RJ)

The referral route depends on the seriousness of the offence: EEI usually involves relatively minor offences and antisocial behaviour whilst DP is used for offences that are considered by referrers more serious (but overall still 'minor' according to the interviewees):

"up until some time ago we would deliver early intervention work on anti-social behaviour for young people [up to 18] who are just on the periphery of offending but actually haven't accumulated any police charges yet. So, we used to have a multi-agency approach run with social work, Police Scotland, community education and ourselves to kind of really think about what the needs are” I. D (third sector, youth RJ)

There are two main models of EEI practice across local authorities in Scotland (Benbow 2019; Gillon 2018). In some local authorities, a multi-agency screening group (involving the police, social work, education, health and third sector organizations) meets regularly to discuss all young people referred to EEI by the police where a decision is made on the most appropriate disposal(s) (e.g. referral to RJ providers). In other local authorities, a 'coordination model' exists where a coordinator makes decisions on the outcome, after requesting information from other agencies. Interviewees reported issues (see below) related to some local authorities' choice to shift from the first to the second model:

"It was a multi-agency meeting. It was the EEI which works in other areas. I would attend that meeting and they would discuss referrals and I would be able to say that's a suitable one for us or whatever. They've stopped that. What the whole system coordinator does is get information from the various schools, health, social work, and makes her decision” I. F (in-house, youth RJ)

\footnotetext{
$\overline{{ }^{12} \text { Scottish public criminal prosecutor }}$
} 
In the case of adult RJ, the referrals can be made via a wider range of routes including selfreferral and involving also serious crimes:

"Well the main referral agency is criminal justice [agencies] and children and family social department in the council. [...] And the Children's Reporter [...]. But we do have a number of [...] people harmed who have referred themselves because they've heard about the project or been involved in" I.K2 (third sector, adult and youth RJ)

"We would have taken referrals for all different types of crimes but we didn't handle domestic violence or sexual violence. It was cases that were suitable for diversion” I.J1 (third sector, adult RJ)

\section{Referrals: Whole System Approach and Diversion from Prosecution}

As well as referring through the EEI route, Procurators Fiscal can make direct (or through social workers) referrals to RJ providers as a DP disposal:

"We do get diversion from prosecution [...] they don't send them directly to us. They'll send them to social work and social work allocates them out to us. So it's kind of like social work are being used as a middle man so to speak. 'I. C (third sector, youth RJ)

A difference between the EEI route and the diversionary/disposal referrals is that for the latter, the case assessment is carried out individually by the Procurator Fiscal. A few interviewees stated that Procurators Fiscal were not always aware of RJ being available in their area, posing questions regarding the quantity and type of cases actually referred to RJ providers through this route (see 4.3.1):

"...A lot of the time it was where both parties were identified by the Procurator Fiscal as being suitable for a restorative intervention. It was when the person harmed had a low level offence, usually first time, and was suitable for diversion" I.J2 (third sector, adult RJ)

"So it's like some of the Procurators Fiscal are educated - know that this [RJ] is what's in the area that I'm marking in - and some of the Fiscals don't know, so [...] they still won't signpost it to us" I. C (third sector, youth RJ)

Interviewees particularly stressed the difference between EEI and DP in terms of procedural constraints to referrals and outcomes:

"We used to get DP [...] I think what we realised was that it was very prescriptive so the courts or the fiscal service really wanted a set programme of here's what that persons been through, here's their compliance levels, and give me a report to let me know that they've done that" I. I (in-house, adult and youth RJ)

Overall, it appears that RJ within this system is primarily a measure for young people, involved in minor offending, as a first (or early) offence-somehow contrasting with the more expansive, even radical understanding of RJ held by practitioners.

\section{'Full Support Package'}

A distinctive feature of local $\mathrm{RJ}$ provision is that practitioners often perform other offending-related interventions integral to local authorities' social services and for this reason they are usually able to provide a 'full support package' for people (both young and adults) referred to them. This applies both to services delivered in-house by local authority staff and those contracted to a third sector 
organization. This feature is related to the fact that in Scotland services for and supervision of offenders in the community are provided and coordinated not by a probation service, but by local authority social work departments, under The Social Work (Scotland) Act (1968) (Brodie et al. 2008). This is a vital contextual factor for the organization of both community justice and RJ services:

"So we're contracted to deliver four tiers of intervention. So the first tier would be early intervention where we could look at preventative kinds of measures [...].Second tier would be looking at where a young person has accumulated charges [...], to undertake a specific piece of work to minimise the risk of reoffending. Third tier would be where a young person got maybe some sort of welfare issues or [has] offended several times and we would work alongside social work to [...] do a piece of work on offending. And the final fourth tier would be to deliver a service called diversion from prosecution [...] to do a piece of work as an alternative to court prosecution" I. D (third sector, youth RJ) "I also have responsibility for adult offenders which would be an employability programme and that is for 16 plus who have had involvement in the criminal justice system at some point. [...] So that's the sort of two main parts [RJ and employability] that I have responsibility for" I. I (in-house, adult and youth RJ)

"So there would be a full support package put around. Where there'd be a restorative option there would be emotional and practical support to the person harmed that runs kind of parallel [...]. Thereafter, once that takes place, we still need to offer some support afterwards” I. B (third sector, youth RJ)

Interviewees rarely saw RJ as a standalone intervention; instead, they argued that it should always be offered as part of a wider package of support focussed on people's needs. Consistently with this perspective, they reported that their main criteria used to decide whether RJ is a suitable option are the presence of an identifiable harmed person (or organization), the needs of the person responsible and the person/organization harmed, and the type/level of offending/harm:

"So we would offer it $[\mathrm{RJ}]$ to anyone that we thought was a need that we could see a good fit for that. I would say probably we use it way more in the young person's service so the EEI service and that's really just because it's, we're easily able to identify persons harmed" I. I (in-house, adult and youth RJ)

"There's no point us going into a case where the person being involved in criminal behaviour for the past three or four years, and they've got twenty odd charges, cause to me that's persistent offending - it's a bit late for us [even though] there's specific crimes that happen in that category that probably could be prevented by adult RJ" I. C (third sector, youth RJ)

\section{System-Level Challenges}

\section{Localism vs. Centralisation}

A specific aim of this project was to identify possible barriers to the provision of RJ in Scotland. Interviewees detailed a range of systemic obstacles to their daily work and to the broader development of RJ. Such challenges relate firstly to a cultural/attitudinal shift in thinking about justice which is yet to be achieved in Scotland:

"I think it's like this massive missed opportunity in general. Scotland is really behind. I think we've got generally a great justice system but why are we not using RJjust everywhere all the 
time? [...] one of the barriers, I suppose, is attitudinal shift, and attitudes to it, because there is that whole thing of being a soft option" I. A (in-house, adult RJ)

Practitioners observed that this attitudinal shift is articulated differently across the country. In certain areas, there is a significant lack of knowledge around (or perhaps resistance to) RJ which translates into the lack of provision or few referrals; in others, RJ has a conspicuous traction expressed by long-lasting provision. Excessive local variations in how referrals are made to RJ were identified as a challenge:

"And I mean even for example if you look at I've got two different areas - I've got XXX and I've got YYY. And you look at them and you say to yourselfyeah they're doing the same thing. I could take a staff out from YYY and put them in XXX and they'd do the same thing. Exactly the same thing. It's not that that's the issue. The issue being is that the information that we get passed across is different in every area and how we get it is different in every area therefore the structure of the model is different" I. C (third sector, youth RJ)

Aside from issues to do with the provision of RJ itself, interviewees identified two more specific barriers: (i) centralisation of prosecutorial marking ${ }^{13}$ and (ii) the reduction of local EEI multi-agency screening meetings:

"I think when we had that relationship locally it was far easier. But when the Procurator Fiscal centralised their markers we didn't have that relationship, we didn't have that reputation for professionalism that we had built over nearly 20 years locally so that did have an impact” I.J1 (third sector, adult RJ)

Eliminating local marking has in fact reduced local contact with RJ providers and hence made referrals slow, scant and often not well-focussed on relevant cases:

"The diversion from prosecution number has significantly reduced so we don't have our local meetings. [...] It's very, very few which is a real shame and it kind of makes me wonder about the bigger picture - where these young people are actually going now? Historically, when we met we had really good contacts with the local Procurator Fiscal who had a really good understanding of services to support the young people" I. D (third sector, youth RJ)

Relatedly, the reduction of local meetings was seen as problematic not only in terms of decreasing opportunities of direct contact with single referrers but also (or perhaps mainly) in terms of limiting RJ practitioners' participation in screening meetings where cases were discussed (i.e. in terms of referrals' quantity and quality):

"We had, until about a year and a half ago, local meetings and they were really helpful. We had partner agencies - social work and the Procurator Fiscal round the table and we had discussions around who was best placed to actually support the young person take the diversion and unfortunately that was then centralised [...] so the local conversations unfortunately were now discontinued" I. D (third sector, youth RJ)

These issues were explained by practitioners as often caused by funding cuts. In fact, third sector providers in particular are reliant on short-term funding for their RJ service which is very much dependent on support at the local level:

13 'Prosecutorial marking' (technically 'Initial Case Processing') refers to prosecutors' decision on a case whether there is a sufficiency of evidence in law for prosecution and whether it is in the public interest to prosecute 
"there was a cut to the funding in that service so it means that we're operating with reduced staffing levels from what we've been used to so that's an obvious challenge" I. B (third sector, youth RJ)

"there's funding available and you go jump on that funding which we did and then that funding goes and so does the service and that's the same for every service." I. I (inhouse, adult and youth RJ)

Overall, these challenges largely concern a tension (well-known in Scotland) between localism and centralisation-between the need for community-facing/locally responsive services and the (supposed) coordination, consistency and efficiency associated with central organizationexacerbated by short-term/inconsistent local funding and public sector austerity (see below).

\section{Information Sharing}

Interviewees described the implementation of the General Data Protection Regulation (GDPR) - the most comprehensive EU regulation on data protection and privacy - as a systemic barrier to the provision of RJ in Scotland and possibly the most recent and most disruptive policy change impacting on their daily work:

"Originally the set-up of the service was to attend EEI meetings with Police Scotland, youth justice assessor, and social work, and the other relevant agencies. That ran well when I started up until May this year [2018] and then with the compliance with the new GDPR law that came out - Police Scotland pulled that from the table. They basically said that they could not share information with us without the consent of the individual and they were having issues gaining consent to do that" I. C (third sector, youth RJ)

Under GDPR, the details of the person harmed (but sometimes also of the young person responsible) cannot be accessed unless the latter has given consent to be contacted. Police and prosecutors often do not offer/discuss $\mathrm{RJ}$ with the person harmed, and $\mathrm{RJ}$ is little known by the broader public. This generates a vicious circle:

"So, prior to GDPR coming into place we would automatically letter victims and we would say you know we understand that you've been a victim of a crime, we're working with the young person, and letting them know what the EEI service is but we don't have a legal basis to do that now so that has like stopped" I. I (in-house, adult and youth RJ)

Interviewees particularly lamented that specific potential referrers (police, councils and prosecutors) do not have GDPR-proofed information sharing protocols:

"We are totally strained. Police Scotland don't have a national directive on this [GDPR]. We're basically being told by national go and sort these things out yourself and come back to us and it's taking forever. [...] I think they [Procurator Fiscals] are a bit less lenient on GDPR than Police Scotland are but at the same time they don't have a directive I think either, which is quite funny because they're to do with the law" I. C (third sector, youth RJ)

Additionally, GDPR has also had an impact by causing the cancellation of some of those screening meetings meant to be a source of referrals to RJ providers. Relatedly, practitioners explicitly linked GDPR with their decreased workload, pointing out to a dynamic which may undermine the continuation of RJ services, due to the lack of demand: 
"It [GDPR] had an impact on accessing people that have been offending actually the referral group that we attend and we're a big part of was cancelled for two months because of GDPR" I. B (third sector, youth RJ)

"We don't have any demand for it [RJ] just now unfortunately... Yeah and I think the demand there is, I suppose the demand is about that victim information" I. I (in-house, adult and youth RJ)

\section{Looking Ahead: Opportunities and Recommendations}

\section{Opportunities}

Overall, interviewees seemed supportive of the recent Scottish policy on RJ mainly for its 'symbolic' value, i.e. since it represents the Government's commitment to develop RJ further:

'I don't think they've [the SG Guidance] had an impact on this service just because it's quite an established service and it's been in existence for a wee while so it's not changed dramatically but I think, I feel a sense of a change in opinions and it's been discussed more because the guidelines have been introduced so I think it's a good thing." I. B (third sector, youth RJ)

"Yeah, really delighted to see that's been considered [Guidance] now and it's a policy we can bring that into our training [...] I think it's a driving force for that." I. H (inhouse, youth RJ)

However, practitioners also maintained that this is just a very preliminary step since financial and operational investments are necessary, underscoring the gap between 'policy in the books' and 'policy in action':

"So I think it's a good workable document but what it obviously needs is then how it is operationalised. It's all well and good having this guidance but then you need all the stuff in place to be able to do RJ'. I. A (in-house, adult RJ)

\section{Recommendations}

Practitioners reflected on a number of ways to tackle the multiple system-level challenges they face daily. Improving information sharing across referrers and providers was certainly a common suggestion, following from the issues related to GDPR:

'But as I say we can't do that [further develop RJ provision] until we've got a really robust information sharing." I. A (in-house, adult RJ)

Associated with the issue of operational models' (excessive) local variations, interviewees recommended a more 'joined up' approach to RJ:

"I think a joined up approach as well because Scotland is a small country but sometimes I just feel like there's pockets of really good knowledge and how can we best share that? If something works in an area can we replicate some of that good practice in other areas as well?" I. D (third sector, youth $\mathrm{RJ}$ ) 
This approach was portrayed as a coordinated range of local multi-agency meetings involving referrers and stakeholders:

"you have to buy in from your statutory authorities and agencies like social work, Police Scotland, NHS even, I think should be involved.” I. C (third sector, youth RJ)

The role of victim support organizations within this context was described by some interviewees as potentially strategic. In fact, only two providers (I.A and I.C) mentioned a current involvement of those organizations (viz. in multi-agency meetings) whilst others emphasized the necessity to overcome some victim organizations' resistance to RJ (cf. Maglione 2020a), leading to their more significant involvement:

"Victim Support across the country, talking about the UK really, not just Scotland, have in the past been quite resistant to being involved with restorative justice because [there is a] sort of almost engrained feeling that you know we're for the offender rather than victim, which is an old fashioned view, but I think it is still there'.'I.K1 (third sector, adult and youth RJ) "But we're talking about making connections with services - victim support services - and they are trained and they can then assess initially and refer into a service like ourselves and then we reassess it again and it's gonna be properly thought through and if it's the right thing to do, then it could be again really powerful." I.J3 (third sector, adult RJ)

Furthermore, practitioners expressed the necessity to widen the spectrum of cases to be referred, not just in terms of quantity (more referrals) but also of quality of cases (i.e. types/ levels of offences):

"I think we tend to get quite low level cases really whereas I think what we know is it's actually more effective with the serious stuff. So I think we're not always targeting the right things. But I think it works with the stuff we do as well so I think there's always benefit from the process." I. E (in-house, youth RJ)

"To be honest, I don't think there's any offences that it can't be used for. [...] That includes sexual offences etc." I. I (in-house, adult and youth RJ)

Finally, they recommended longer-term nationally allocated funding linked to local awareness and support of RJ provision:

"But unless the government and the local authorities can come up with a solution to offer things nationally rather than small pockets of funding then that's the issue we're going to face” I.J1 (third sector, adult RJ)

\section{Discussion}

\section{Welfarism and Restorative Justice}

A key discussion point emerging from our findings is the unique position of RJ practitioners as flexible providers of a menu of options - the 'full support package' approach — informed by two different ethos: RJ itself (Gavrielides 2007: 139; cf. Daly 2016) and a broader 'welfarist' approach (Garland 2001; McAra 2005) which represents the normative backdrop against which RJ is cast. This is possibly related to the deep-rooted role of the welfarist ethos in 
Scottish youth justice arrangements ${ }^{14}$ (McAra 2005), whilst the RJ element is a more recent addition.

'Welfarism', here, refers to a fluid constellation of values such as rehabilitation, promotion of behavioural change, reintegration into community (McAra 2005: 297) and, more recently, multi-agency prevention and actuarialism (Gillon 2018: 57), forming the basis of the Scottish youth justice system. Doing RJ within this context necessarily entails RJ values, aims and practices interacting with the welfarist ethos (cf. Braithwaite 2000: 191; Winslade 2019: 282). This means that welfarism, as a social-structural approach to crime, ends up absorbing individual conflict resolution/relational repair, whilst RJ, inserted in a welfarist context, confronts (and possibly reduces) its oft-lamented individualizing effects on social conflicts (White 2003: 147; Pavlich 2005: 42).

The outcome of this process of integration is the 'full support package' described above. The issue, here, is that the potential of this approach to address complex conflicts and harms by including both individual-relational and social-structural interventions is largely underexploited in practice. The EEI route through which much RJ is done focuses by definition on young people who are involved in low level/early stages of offending. Hence, RJ gets anchored to a preventative approach on minor crimes with limited input from the person harmed (Robertson 2017: 38-39; Scottish Government 2018: 6). The lack of RJ provision for adults and the fact that the person harmed is often 'unreachable' by RJ providers is understandable from this angle. Notably, the two adult RJ providers showed a slightly different approach, where the welfarist element was less emphasized whilst referrals for more serious crime were possible.

The Guidance on the delivery of RJ (2017) has only very partly modified this situation. The idea of a victim-sensitive and wide-reaching RJ clashes against referrers' organizational models and culture. The gap between policy and practice seems to arise from the discrepancy between how referrers understand and use RJ - a response for petty crimes committed by youths, chiefly justified by a non-stigmatizing approach and with victims as optional participants - and how RJ practitioners (partly echoed by the Guidance) understand their work, a 'social RJ' able to work with persons harmed and responsible, in a wide variety of cases (including serious harms).

This discrepancy will likely be an issue for the future development of RJ in Scotland and for the implementation of both the Guidance and the Action Plan. Although the Guidance offers a common 'symbolic' benchmark, it appears that the organizational cultures in action here continue to drive referrers and practitioners apart (cf. ICPR 2016: 7).

\section{Localisation vs. Centralisation}

One of the system-level challenges highlighted by participants was the high degree of local variations in the organization of referral routes and its impact on the provision of RJ. This is explained by the fact that the WSA operates in partnerships at local authority level, with significant flexibility to suit local arrangements and demographics (Benbow 2019; Gillon 2018: 55). This means that both EEI decision-making processes (e.g. attendance in multiagency meetings, information sharing, etc.) and the extent of agency involvement vary significantly (Robertson 2017: 50-51). The Scottish Government did try to reduce this

\footnotetext{
${ }^{14}$ The inception of this ethos is linked with the Kilbrandon Committee's Report (1964) which inspired the Social Work (Scotland) Act 1968, setting out a single system where the welfare of children, including those involved in offending, would be protected focussing on needs and not only deeds
} 
fragmentation by issuing a specific guidance on EEI characterized by a standard menu of disposals available to decision-makers ${ }^{15}$ (Scottish Government 2015). However, as participants pointed out, the inconsistencies are linked not to the options menu but to referral routes and lack of common inter-organizational protocols across different local authorities. This resonates with the Scottish Government survey on RJ which found emphasis from respondents on the lack of 'clear structure and understanding of the principles from all stakeholders' (Scottish Government 2018: 8).

Similarly, RJ as a DP is characterized by heterogeneity (cf. Bradford and MacQueen 2011). The centralisation of prosecutorial marking in 2015 may have partly addressed this issue but at the same time has opened a new problematic front. In fact, it appears that eliminating local marking has reduced local contact with RJ providers and therefore has made referrals slow and often not well focussed on relevant cases.

This issue should be placed in a broader context, that is, the political dialectic between central and local government in Scotland, within and beyond criminal justice, exacerbated by recent austerity public funding cuts.

The current 32 local authorities in Scotland were created in 1996 on the back of years of critique of previous local government arrangements, to gather all local services under one roof (Buchan and Morrison 2020). This system was partly modified from 2007 when the Scottish National Party (SNP) agreed to increased local flexibility and autonomy, in return for a long council tax freeze. More recently, the 2016 Community Justice (Scotland) Act shifted the responsibilities of coordinating and overseeing community justice commissioning and delivery (including the organization of youth justice) to new partnerships at local authority level, simultaneously creating a national body (Community Justice Scotland) to provide leadership and raise public and political awareness. This reform has created significant disruption and expense for provider organizations and contributed to the further fragmentation of an already complex community justice landscape (Buchan and Morrison 2020; Nolan 2015). Austerity funding cuts have fed into such a complex political-legal dynamic. In Scotland, 'austerity' has meant scaling back and prevention-focused reorientation of government functions in response to budgetary pressures, rather than their outright withdrawal (McKendrick et al. 2016). The central government continues to grant social protection, although not at previous levels and not always as directly. This gives local authorities power, but also shifts risk on them to arrange services, hence fuelling variation whilst reducing either provision or staff levels.

\section{Information Sharing}

The operational difficulties lamented by interviewees have been further intensified by the slow implementation of the GDPR. This resonates with the findings of the Scottish Government survey on RJ where respondents highlighted that 'Information sharing constraints limit [the] potential [of RJ]' (Scottish Government 2018: 8) and with the Action Plan, which built on that survey (Scottish Government 2019: 10).

The main issue here is that the victim's details are personal data, whose controller is not the local authority or the third sector RJ provider (which play the role of processors), but police and or Procurators Fiscal who have to implement data protection 'by default' (Information Commissioner's Office 2019a: 24). The consent provided by the victim is the main legal basis

\footnotetext{
$\overline{15}$ They are no further action, police direct measures, single agency support, referral to targeted intervention (e.g. RJ, substance misuse) and referral to Children's Reporter
} 
for such personal data processing. To obtain such a consent requires by default an evidenced, positive opt-in (making pre-ticked boxes illegal) as well as easy withdrawal. This renders data processing relatively burdensome and the development of both internal protocols and interorganizational information sharing agreements particularly difficult. This situation resonates with the findings of the Information Commissioner's Office's (ICO) Good Practice department survey on information governance practices in local government in the UK (ICO 2019b). The ICO found out that $37 \%$ of councils have no data sharing policy, despite increasing data sharing requirements to offer certain services. Additionally, the slow implementation of GDPR may be related to the GDPR's actual novelty (with respect to the 1998 Data Protection Act), that is, a new regime of accountability including the ability of regulators to hit controllers who do not comply with considerably large fines (Layton 2017).

Overall, it is essential to take into account the complexity of the information sharing in this context, characterized by public-public and public-third sector collaborations (Purtova 2018). This complexity, backed up by financial threats in a time of austerity, may explain the belated development of information sharing protocols. Such a slowness amounts to an increased legal uncertainty for both data controllers and processors and leads to practical difficulties (if not paralysis) among RJ providers, local authorities and referrers (cf. Marquenie 2017: 329).

\section{Implications: Policy, Practice and Research}

A number of implications can be drawn from this research, pertaining to the relationships between policy and practice, the future of RJ in Scotland and the development of research. Some of these reflections may apply to the wider development of RJ in Europe.

The commonalities between interviewees' understandings of RJ and the recent policy represent a favourable condition for the expansion of RJ in Scotland. Such commonalities relate mainly to some of the basic values underpinning RJ, such as appropriateness and voluntary access. Interviewees (echoed by the Guidance) think that RJ should have a wider range of both youth and adult referrals. Moreover, there is overlap between some of the system-level challenges reported by our informants and the obstacles to the expansion of RJ in Scotland acknowledged by the Action Plan (viz. information sharing and lack of resources).

However, there are also significant differences between policy and practice. The Guidance still appears contaminated by criminal justice jargon with its insistence on 'victims' and 'offences', whilst interviewees emphasized the need to talk of 'person harmed' (also the expression used by the Action Plan) and 'harm' - consistently with their critique of criminal justice (as well as with the recent Council of Europe Recommendation CM/Rec(2018)8 on $\mathrm{RJ})$. Additionally, policy does not seem to fully appreciate the distinctiveness of RJ done in Scotland (youth-focused and infused with welfarist values). Here, there seems to be a rift between policymakers and practitioners which could be addressed by investing further in knowledge exchanges between people working on the frontline, i.e. policy teams and RJ providers. This could be done by supporting the Scotland RJ Forum ${ }^{16}$ (and particularly the Practitioners Forum which has been constituted within the Forum) as a venue for regular interorganizational meetings.

The complex relationships between RJ policy and practice are not simply a Scottish phenomenon. As it is well-known within socio-legal studies (and as our findings confirm),

${ }^{16}$ Advocacy group which gathers professionals, volunteers and researchers interested in RJ 
professionals filter policy texts in light of their organizational/personal culture and other contingent factors, sometimes using policy to justify ex-post their discretionary decisions (Cotterrell 2007). This would suggest a nuanced critical assessment of the incorporation of RJ into policy frameworks (Maglione 2020a), a phenomenon which has now worldwide dimensions (Poama 2015). New policy frameworks may have a symbolic value but, as our interviewees reported, existing professional cultures, organizational strengths and challenges shape the actual provision of RJ.

The problematic dynamic between localisation and centralisation of operational models, and mainly of referrals routes, does not have a direct resonance with existing Scottish policy, unless we consider this as the Guidance's implicit premise. The Action Plan (2019: 10) possibly hints at this subject when discussing the necessity to increase the provision of training. ${ }^{17}$ The issue of fragmentation/centralisation would require to be discussed more directly and thoroughly. The creation of cross-local authority hubs could help reduce fragmentation, whilst still ensuring crucial links with local contexts. One central, state-run RJ hub, instead, should be discouraged. Interviewees took for granted the community-based nature of $\mathrm{RJ}$ and, although fragmentation is an issue, centralisation seems to run counter to the approach embraced by practitioners.

This dynamic has a wider, international saliency. Centralizing the provision of RJ services may appear as a step toward the expansion of RJ (in terms of implementation, funding and capacity); however, this process may re-shape (i.e. bureaucratise and standardize) the functioning of RJ (cf. Gavrielides 2007, 2016). This 'operational' issue, in fact, entails a possible deterioration of some of the basic RJ values - de-professionalization, critique of punishment, direct stakeholders' centrality and cooperative-transformative approach to social conflicts and harms (Maglione 2020b). Our study shows that practitioners do not call for centralisation, but for nationwide funding distribution and inter-agency cooperation (i.e. a 'joined up' approach).

In terms of public awareness, the main challenge is referrers' awareness and not (only) broad public awareness. Raising general public awareness instead should be handled with care. The current capacity to provide RJ in Scotland seems limited, patchy and currently affected by multiple challenges, as our findings show. Generating demand without tackling those systemic obstacles would equate with RJ losing credibility, impinging on future developments. Instead, involving referrers should become a top priority on the Scottish RJ movement's agenda.

Regarding referrals, the point is not simply increasing their number (i.e. more RJ, as the Action Plan suggests (2019: 10)), but their quality-i.e. ensuring that referrers make relevant referrals, which also means adult cases and more serious offences/harms.

Currently, whilst a practice-based approach to youth RJ is already available, underpinned by certain values and implemented by certain actors, as our findings show, there are no solid adult RJ models in Scotland. This sector has to be entirely re-imagined, considering, for instance, how to promote self-referrals or referrals from within the community, or, more broadly, how a 'social RJ' would work for adults (cf. Kirkwood and Hamad 2019).

Multi-agency work is key here. This is a real challenge but also where opportunities for a 'better' RJ in Scotland lie. Ensuring that multi-agency screening meetings take place locally and regularly and that RJ providers' representatives take part in such meetings is crucial. This could be further facilitated by the identification of RJ champions in local authorities, as the Action Plan also suggests (2019: 10). In order to deal with the limited input from people harmed, victims organizations' involvement is recommended. In fact, when police and

$\overline{17}$ This did not emerge from our findings as a priority for practitioners 
prosecutors fail to offer RJ to the person harmed, victim support organizations could still describe RJ to their clients, in lieu of those traditional gatekeepers.

A multi-agency referral approach has already a British (Chapman 2012; Crawford and Newburn 2003) and European (e.g. Norway (Holmboe 2017)) currency. Existing experiences in this area suggest that this may ensure a more holistic assessment of possible referrals. Nevertheless there are also some potential issues to be considered here (Christie 2015). This approach lends itself to the cooptation of RJ (i.e. the subjection to conventional criminal justice values and goals) and often does not include a direct input either from the person harmed/who has harmed or from their social networks. A crucial, preliminary step to unravel this type of challenge is deciding whether RJ is (and ought to be) another way of doing criminal justice (in which case cooptation is not an issue), or a completely different justice approach, based on distinctive values. This decision pertains to the RJ movement and requires a normative reflection on the toll to be paid when mixing $\mathrm{RJ}$ with criminal justice.

The issues related to the GDPR are structural and Europe-wide (as are the lack of national funding and austerity cuts) and cannot be addressed here for limits of space. Suffice it to say that local authorities, providers and referrers need to develop information sharing protocols urgently, possibly working toward a future network governance approach (law enforcement authorities and third sector parties determining purposes and means of information sharing as joint controllers, and in some cases even as equal partners).

Finally, there are two significant and interrelated implications for future comparative research. Our study shows that the generation of RJ ideals is not only and merely an endeavour put forth by advocates or academics but (also) the outcome of the organic interaction between (some) basic RJ values, existing professional ethos and local organizational frameworks. Future comparative research should address such a bottom-up dynamic, its premises and outcomes, looking at how it unfolds in different national contexts. This may enrich our understanding of RJ models also providing preliminary material to reflect critically and in a context-sensitive way on the 'effectiveness' of RJ.

The second implication is related to the potential of a 'social justice-oriented RJ'. Interviewees showed that the combination between (particularly youth) RJ and a welfarist ethos is possible provided that it is supported by referral routes, coordinated inter-organizational arrangements and agencies familiar with RJ. The critique of RJ as individualizing social conflicts and harms is still relevant (Pavlich 2005), but, as the Scottish case shows, it is possible to embed (although precariously) RJ in a wider social approach to harms, which includes a variety of tools, e.g. education, rehabilitation, training, etc., which would 'socialize' RJ dialogues. This subject certainly needs further theoretical elaboration and empirical research, which may possibly lead to rethinking some of the critiques levelled against RJ.

\section{Conclusions}

This exploratory study has generated original insights into the provision of RJ within Scottish local authorities whilst considering their implications. The findings reveal context-specific understandings of RJ (an ethos informing specific practices), recurrent organizational features (youth-centred preventative services within the WSA framework) as well as common systemlevel challenges (referrers' lack of buy-in, information sharing, fragmentation, funding cuts).

Overall, it emerges that RJ in Scotland is construed as a one-off reaction to minor crimes committed by one-time youth offenders, and not a response to complex social harms. Whilst 
these representations can be found also in other geographical contexts, in Scotland their organizational, cultural and political background is characterized by some specific features.

The main role in shaping operationally this RJ is played less by practitioners (who firmly believe and look forward to tackling complex cases) and more by referrers, who appear to see $\mathrm{RJ}$ as a 'lower rank justice' ancillary to penal responses inspired by Scottish penal welfarism, envisioning an implicit competition (or at least a very uneven labour division) between these two models. Practitioners, instead, show that a social justice-oriented RJ is possible, but there is a need to get referrers 'on board', creating information-sharing GDPR-proofed protocols and providing structural/nationwide funding. Policy seems only partly receptive of practitioners' characteristics, challenges and needs, posing questions on how to facilitate a more sensitive bottom-up contact between policy teams and providers.

The problematic dynamic between localisation/centralisation of referrals and provision of $\mathrm{RJ}$ is a further crucial finding, with a wider international saliency. Here, as elsewhere in Europe (Gavrielides 2016), striking this balance is a challenge, given the detrimental effects of the centralisation of criminal justice services (exemplified in Scotland by reforms to prosecutorial marking). Investing in bottom-up initiatives, cross-local screening hubs and information sharing is a possible route to tackle this issue. More broadly, any ambition to generate a RJ national model needs to be addressed critically. The idea of 'modelling' bottom-up social processes (including justice practices like $\mathrm{RJ}$ ) is predicated on a deterministic understanding of the social world as an infinitely plastic matter to be shaped according to the intentions and goals of policy and academic architects (cf. Maglione 2020b). This is a controversial approach resting on a disputed premise, whilst acknowledging the field of tensions which characterizes $\mathrm{RJ}$, listening to practitioners and respecting the plurality of their needs, their common strengths and challenges appear as a more sensible way to think about the future of RJ in context.

Policy, as our interviewees highlighted, may play a symbolic role in driving change, but there is a need to overcome systemic challenges and reflect on the context-specific practice-led uniqueness of Scottish RJ, particularly if any ambitious promise of making RJ widely available in this context is to be honoured.

Acknowledgements We wish to thank Sally Brown and the attendees of the European Society of Criminology annual conferences 2019 and 2020 for their feedback on an early draft of this article.

Open Access This article is licensed under a Creative Commons Attribution 4.0 International License, which permits use, sharing, adaptation, distribution and reproduction in any medium or format, as long as you give appropriate credit to the original author(s) and the source, provide a link to the Creative Commons licence, and indicate if changes were made. The images or other third party material in this article are included in the article's Creative Commons licence, unless indicated otherwise in a credit line to the material. If material is not included in the article's Creative Commons licence and your intended use is not permitted by statutory regulation or exceeds the permitted use, you will need to obtain permission directly from the copyright holder. To view a copy of this licence, visit http://creativecommons.org/licenses/by/4.0/.

\section{References}

Benbow, N. L. (2019). Preventing youth crime in Scotland: The practices of early intervention and diversion under 'Whole System Approach' implementation. PhD thesis. https://dspace.stir.ac.uk/bitstream/1893/29670/ 1/Final\%20Draft\%20Revised\%20May\%202019.pdf. Accessed 25 May 2020.

Bradford, B., \& MacQueen, S. (2011). Diversion from prosecution to social work in Scotland: A snapshot of current patterns and an examination of practice in three CJA's. Glasgow: SCCJR. 
Braithwaite, J. (2000). Restorative justice and social justice. Saskatchewan Law Review, 63, 185-194.

Braun, V., \& Clarke, V. (2006). Using thematic analysis in psychology. Qualitative Research in Psychology, 3(2), 77-101.

Brodie, I., Nottingham, C. \& Plunkett, S. (2008). A Tale of Two Reports: Social Work in Scotland from Social Work and the Community (1966) to Changing Lives (2006). British Journal of Social Work, 38(4), 697715 .

Buchan, J., \& Morrison, K. (2020). Compromise, partnership, control: Community Justice Authorities in Scotland. Criminology \& Criminal Justice, 20(2), 226-243.

Centre for Youth and Criminal Justice (CYCJ) (2018). A guide to youth justice in Scotland: Policy, practice and legislation. https://www.cycj.org.uk/resource/youth-justice-in-scotland-guide/. Accessed 25 May 2020.

Chapman, T. (2012). The problem of community in a justice system in transition: The case of community restorative justice in Northern Ireland. International Criminal Law Review, 12(3), 573-588.

Christie, N. (2015). Widening the net. Restorative Justice: An International Journal, 3(1), 109-113.

Cotterrell, R. (2007). Law, culture and society: Legal ideas in the mirror of social theory. London: Routledge.

Crawford, A., \& Newburn, T. (2003). Youth offending and restorative justice: Implementing reform in youth justice. Devon: Willan.

Croall, H. (2006). Criminal justice in post-devolutionary Scotland. Critical Social Policy, 26(3), 587-607.

Daly, K. (2016). What is restorative justice? Fresh answers to a vexed question. Victims \& Offenders, 11(1), 929.

Dutton, K., \& Whyte, B. (2006). Implementing restorative justice within an integrated welfare system: The evaluation of Glasgow's restorative justice service: Summary report. Edinburgh: CJSWDC.

Garland, D. (2001). The culture of control: Crime and social order in contemporary society. Oxford: Oxford University Press.

Gavrielides, T. (2007). Restorative justice theory \& practice: Addressing the discrepancy. HEUNI: Helsinki.

Gavrielides, T. (2016). Repositioning restorative justice in Europe. Victims \& Offenders, 11(1), 71-86.

Gillon, F. (2018). Early and effective intervention (EEI) in Scottish youth justice: Benevolent principles and unintended consequences. PhD Thesis. https://pureportal.strath.ac.uk/en/studentTheses/early-and-effectiveintervention-eei-in-scottish-youth-justice-be. Accessed 01 April 2020.

Holmboe, M. (2017). Norwegian youth punishment - Opportunity or trap? Bergen Journal of Criminal Law \& Criminal Justice, 5(1), 37-58.

Information Commissioner's Office (2019a). Guide to the General Data Protection Regulation (GDPR). https:// ico.org.uk/media/for-organisations/guide-to-data-protection/guide-to-the-general-data-protection-regulationgdpr-1-0.pdf. Accessed 11 May 2020.

Information Commissioner's Office (2019b). Good practice department survey on information governance practices in local government in the UK. https://ico.org.uk/media/2013721/local-government-informationgovernance-survey-results-20170320.pdf. Accessed 11 May 2020.

ICPR (2016). Report of a mapping exercise of restorative justice provision in England \& Wales for the Restorative Justice Council.https://restorativejustice.org.uk/resources/mapping-report-restorative-justiceprovision-england-and-wales-2016. Accessed 1 April 2020.

Kearney, N., Kirkwood, S., \& MacFarlane, L. (2006). Restorative justice in Scotland: An overview. British Journal of Community Justice, 4(3), 55-65.

Kearney, N., Kirkwood, S., \& MacFarlane, L. (2009). Restorative justice (diversion) services monitoring and evaluation report 2006/07. Edinburgh: Sacro.

Kirkwood, S. (2009). Restorative justice cases in Scotland: Factors related to participation, restorative process, agreement rates and forms of reparation.http://www.restorativejusticescotland.org.uk/Article_on_RJ_ Cases_in_Scotland_18-06-09.pdf. Accessed 12 April 2020.

Kirkwood, S., \& Hamad, R. (2019). Restorative justice informed criminal justice social work and probation services. Probation Journal, 66(4), 398-415.

Layton, R. (2017). How the GDPR compares to best practices for privacy, Accountability and Trust. https://ssrn. com/abstract=2944358. Accessed 01 November 2019.

Maglione, G. (2020a). Restorative justice, crime victims and penal welfarism. Social \& Legal Studies, https://oi. org/10.1177/0964663920965669.

Maglione, G. (2020b). Restorative justice and the State. Untimely objections against the institutionalisation of restorative justice. British Journal of Community Justice, https://www.mmuperu.co.uk/bjcj/articles/ restorative-justice-and-the-state.-untimely-objections-against-the-institut. Accessed 19 November 2020.

Marquenie, T. (2017). The police and criminal justice authorities directive: Data protection standards and impact on the legal framework. Computer Law and Security Review, 33(3), 324-340. 
Marshall, T. (1999). Restorative Justice: An Overview. http://www.homeoffice.gov.uk/rds/pdfs/occ-resjus.pd. Accessed 01 November 2019.

McAra, L. (2005). Modelling penal transformation. Punishment and Society, 7(3), 277-302.

McKendrick, J., et al. (2016). Conceptualising austerity in Scotland as a risk shift: Ideas and implications. Scottish Affairs, 25(4), 451-478.

Miers, D. (2004). Situating and researching restorative justice in Great Britain. Punishment \& Society, 6(1), 2346.

Nicol, W., Kirkwood, S. \& MacFarlane, L. (2006). Youth justice services evaluation report: April 2004-March 2005.https://www.sacro.org.uk/YJ_Eval_Report.pdf. Accessed 12 November 2019.

Nolan, D. (2015). Youth justice: A study of local authority practice across Scotland. http://www.cycj.org.uk/wpcontent/uploads/2015/07/Youth-Justice-A-Study-of-Local-Authority-Practice-Across-Scotland-FINAL.pdf. Accessed 12 April 2020.

O'Reilly, M., \& Kiyimba, N. (2015). Advanced qualitative research. London: SAGE.

Pavlich, G. (2005). Governing paradoxes of restorative justice. London: Glasshouse.

Poama, A. (2015). Restorative justice: The institutional turn. Raisons politiques, 59(3), 7-16.

Purtova, N. (2018). Between the GDPR and the police directive: Navigating through the maze of information sharing in public-private partnerships. International Data Privacy Law, 8(1), 52-68.

Robertson, L. (2017). A practice-based approach to youth justice: The whole system approach in Scotland. PhD thesis. http://theses.gla.ac.uk/8493/. Accessed 16 April 2020.

SCCJR \& Viewpoint (2009). National evaluation of restorative justice youth services in Scotland. http://www. sacro.org.uk/RJ_Evaluation_Report_2008-2009.pdf. Accessed 12 November 2019.

Scottish Justice Matters (2017). Monographic issue on restorative justice. http://scottishjusticematters.com/thejournal/restorative-justice-april-2017/. Accessed 03 March 2020.

Warner, S. (1992). Reparation, mediation and Scottish criminal justice. In H. Messmer \& H.-U. Otto (Eds.), Restorative justice on trial: Pitfalls and potentials of victim-offender mediation - International research perspectives (pp. 197-210). Springer.

White, R. (2003). Communities, conferences and restorative social justice. Criminal Justice, 3(2), 139-160.

Winslade, J. (2019). Can restorative justice promote social justice? Contemporary Justice Review, 22(3), 280289.

Wood, W., \& Suzuki, M. (2016). Four challenges in the future of restorative justice. Victims \& Offenders, 11(1), $149-172$.

Policy

\section{European Union}

Regulation (EU) 2016/679 on the protection of natural persons with regard to the processing of personal data and on the free movement of such data, and repealing directive 95/46/ec (General Data Protection Regulation).

Directive 2012/29/EU of the European Parliament and the Council of 25 October 2012 establishing minimum standards on the rights, support and protection of victims of crime, and replacing Council Framework Decision 2001/220/JHA.

\section{Council of Europe}

Recommendation CM/Rec(2018)8 of the Committee of Ministers to member States concerning restorative justice in criminal matters.

\section{Scotland}

The Social Work (Scotland) Act (1968).

The Victims and Witnesses (Scotland) Act (2014).

The Criminal Justice and Licensing (Scotland) Act (2010).

The Community Justice (Scotland) Act (2016). 
Scottish Government (2019). Restorative justice: Action Plan. https:/www.gov.scot/publications/restorativejustice-action-plan/. Accessed 01 February 2020.

Scottish Government (2018). Restorative justice - Baseline survey report February 2018. https://www.gov.scot/ publications/restorative-justice-survey-response-analysis/ Accessed 16 April 2020.

Scottish Government (2017). Guidance for the delivery of restorative justice in Scotland. https://beta.gov.scot/ publications/guidance-delivery-restorative-justice-scotland/pages/4/. Accessed 16 March 2020.

Scottish Government (2016). Whole system approach for young people who offend [online]. http://www.gov. scot/Topics/Justice/policies/young-offending/whole-system-approach. Accessed 16 March 2020.

Scottish Government (2015). Early and effective intervention - Framework of core elements www2.gov.scot/ Publications/2015/03/6818. Accessed 16 April 2020.

Scottish Government, (2008). Restorative justice services - For children and young people and those harmed by their behaviour https://www2.gov.scot/Publications/2008/06/10143757/1. Accessed 07 March 2020.

Scottish Government (2005). Restorative justice services in the Children's Hearings System national guidelines https:/www2.gov.scot/Publications/2005/07/11160004/00062. Accessed 21 January 2020.

Scottish Government, Children's Reporter and Association of Chief Police Officers in Scotland (2004). Restorative warnings in Scotland - Guidelines for police https://www2.gov.scot/Publications/2004/06/ 19497/38779. Accessed 20 May 2020.

Scottish Government (2002a). National standards for Scotland's youth justice services https:/www2.gov.scot/ Publications/2002/12/16030/15870. Accessed 21 January 2020.

Scottish Government (2002b). Scotland's Action Programme to Reduce Youth Crime https://lx.iriss.org.uk/ content/scotland\%E2\%80\%99s-action-programme-reduce-youth-crime-2002. Accessed 01 April 2020.

\section{England \& Wales}

The Crime and Courts (England \& Wales) Act (2013) http://www.legislation.gov.uk/ukpga/2013/22/pdfs/ukpga 20130022 en.pdf. Accessed 01 February 2020.

\section{Northern Ireland}

The Justice (NI) Act (2002) http://www.legislation.gov.uk/ukpga/2002/26/contents. Accessed 07 October 2019.

Publisher's Note Springer Nature remains neutral with regard to jurisdictional claims in published maps and institutional affiliations. 